\title{
ANALISIS BEBAN KERJA SEBAGAI DASAR PERENCANAAN KEBUTUHAN PEGAWAI
}

Submitted Date :

25 Juni 2020

Accepted Date :

02 November 2020

\author{
Hamidah Nayati Utami \\ Universitas Brawijaya Malang \\ hamidahn@ub.ac.id
}

Arik Prasetya

Universitas Brawijaya Malang arik_p_fia@ub.ac.id

Muhammad Rosyihan Hendrawan
Universitas Brawijaya Malang
endralife@gmail.com

Suggested Citation:

Utami, HN, Afrianty, TW, Sari, RW, (2019) Beban kerja dan pengaruhnya terhadap komitmen organisasional dengan stres kerja sebagai variabel intervening, Jurnal Bisnis Terapan Vol 3 No 2, es 2019, Politeknik Ubaya, Surabaya.

Abstract:

The purpose of this study is to determine the amount of use of work time required by education staff, determine the optimal number of educational workforce requirements in accordance with standards, and explain the recommendations for universities in planning optimal employee needs. This study analyzes the workload of educational staff in providing services in one of the Faculties at Brawijaya University. The number of employees analyzed was 86 education personnel working in four subdivisions in One Faculty. This type of research is a qualitative descriptive study with data collection techniques: documentation, observation, interviews, and focus group discussions. Data analysis techniques use an interactive model that is carried out continuously until there is data saturation. The results of the analysis show that: there are 4 categories of use of work time namely overload, fit, underload, and critical underload which are the results of real time verification used to complete basic and additional work compared to ministerial standards. The total need for education personnel after verification is 84 people. Recommendations on manpower planning are: restructuring of education personnel based on the number needed in each sub-section, simplifying tasks so as to reduce work time, optimizing the use of technology as a tool to reduce work time, placing employees in accordance with the qualifications required for each task.

Keywords Human Resource Planning, Manpower Planning, Working Time, Workload.

\begin{abstract}
Abstrak
Tujuan penelitian ini adalah untuk mengetahui jumlah penggunaan waktu kerja yang dibutuhkan tenaga kependidikan, menentukan jumlah kebutuhan tenaga kependidikan yang optimal sesuai dengan standar, dan menjelaskan rekomendasi bagi perguruan tinggi dalam melakukan perencanaan kebutuhan pegawai yang optimal. Penelitian ini menganalisis beban kerja yang ditanggung oleh tenaga kependidikan dalam memberikan pelayanan di salah satu Fakultas di Universitas Brawijaya. Jumlah pegawai yang dianalisis adalah 86 orang tenaga kependidikan yang bekerja di empat sub bagian di Satu Fakultas. Jenis penelitian adalah penelitian deskriptif kualitatif dengan teknik pengumpulan data: dokumentasi, observasi, wawancara, dan focus group discussion. Teknik analisis data menggunakan model interaktif yang dilakukan secara terus menerus sampai terdapat kejenuhan data. Hasil analisis menunjukkan bahwa: terdapat 4 kategori penggunaan waktu kerja yaitu overload, fit, underload, dan critical underload yang merupakan hasil verifikasi waktu riil yang digunakan untuk menyelesaikan pekerjaan pokok dan tambahan dibandingkan dengan standar kementerian. Adapun total kebutuhan tenaga kependidikan setelah verifikasi adalah 84 orang. Selanjutnya rekomendasi yang diberikan untuk Universitas Brawijaya dalam perencanaan kebutuhan tenaga kependidikan adalah: melakukan penataan tenaga kependidikan sesuai dengan jumlah yang dibutuhkan pada masing-masing sub bagian, membuat penyederhanaan tugas yang memungkinkan pengurangan waktu yang dibutuhkan, mengoptimalisasikan penggunaan teknologi sebagai alat bantu untuk memangkas waktu kerja, menempatkan pegawai sesuai dengan kualifikasi yang dibutuhkan pada masing-masing tugas.
\end{abstract}

Kata Kunci: Beban Kerja, Kebutuhan Pegawai, Perencanaan Sumber Daya Manusia, Waktu Kerja.

JEL Classification: 015 


\section{Latar Belakang}

Dewasa ini, tuntutan masyarakat terhadap pelayanan publik semakin besar, namun profesionalisme yang diharapkan belum sepenuhnya terwujud. Untuk mengantisipasi perubahan global yang cepat seperti yang terjadi pada era saat ini yang mana seiring dengan perkembangan revolusi industri 4.0, sebuah organisasi harus membangun tata kelola organisasi perguruan tinggi yang lebih dinamis (dynamic governance), dimana organisasi dapat menyesuaikan kebijakan dengan perubahan lingkungan global yang cepat dan tidak menentu sehingga tujuan organisasi tetap dapat diwujudkan. Penelitian yang dilakukan oleh Houston et al., (2006) menunjukkan bahwa Staf akademik universitas melakukan pekerjaan yang kompleks dalam lingkungan yang semakin menuntut karyawan bekerja dengan menyesuaikan perubahan lingkungan.

Begitu juga Universitas Brawijaya (UB) sebagai sebuah organisasi dalam rangka meningkatkan profesionalisme sumber daya manusianya juga belum optimal. Dalam kaitan tersebut UB perlu memperbaiki tatakelola organisasi yang ada dengan memberi perhatian kepada pembangunan SDM, khususnya untuk dapat melahirkan para pemimpin birokrasi yang mampu berfikir ke depan (thinking ahead), mengkaji ulang (thinking again) dan belajar dari negara atau organisasi lain (thinking across). Salah satu penyebab utama belum optimalnya kinerja tenaga kependidikan tersebut adalah distribusi tenaga kependidikan pada suatu unit kerja atau satuan kerja belum mengacu pada kebutuhan organisasi yang sebenarnya, dalam arti belum didasarkan pada beban kerja yang ada. Menumpuknya tenaga kependidikan di satu unit kerja dan kurangnya tenaga kependidikan di unit kerja yang lain merupakan suatu contoh yang nyata dari permasalahan tersebut. Permasalahan sebenarnya bukan terletak pada jumlah tenaga kependidikan yang terlalu besar, namun pada distribusi tenaga kependidikan yang tidak sesuai kebutuhan dan pekerjaan.

Langkah penting dalam mengatasi permasalahan ketidaksesuaian jumlah tenaga kependidikan adalah melaksanakan Analisis Beban Kerja. Analisis beban kerja dilakukan dengan pertimbangan bahwa Sumber Daya Manusia merupakan asset yang harus dikelola dengan baik agar Visi, Misi dan Tujuan serta sasaran organisasi dapat tercapai dengan baik. Optimalisasi pemberdayaan kapasitas Sumber Daya Manusia dengan alokasi beban kerja dan jabatan dapat memotivasi kerja tenaga kependidikan. Analisis Beban Kerja perlu dilakukan agar dapat menempatkan tenaga kependidikan sesuai dengan porsi kerja dengan posisi jabatan yang menjadi tanggung jawabnya, juga untuk memperoleh gambaran apakah langkah- langkah pembenahan dan perbaikan diperlukan didalam pemetaan kompetensi tenaga kependidikan dan mengevaluasi struktur organisasi yang ada.

Sumber daya manusia pada setiap unit harus dapat dikelola dengan baik terutama agar beban kerja yang ditanggung oleh masing-masing tenaga kependidikan sesuai dengan kapasitas yang dimiliki. Jika terjadi kelebihan beban kerja, maka para tenaga kependidikan akan merasa kelelahan dalam melayani kebutuhan administrasi dan dapat berakibat menurunnya kualitas pelayanan. Sebaliknya jika terjadi kekurangan beban kerja, maka institusi menggaji tenaga kependidikan dengan jumlah yang lebih banyak untuk hasil kerja yang sama atau terjadi inefisiensi biaya. Tenaga kependidikan yang tidak dapat bekerja optimal sesuai kapasitasnya dapat berakibat terganggunya proses pencapaian tujuan organisasi.

Berdasarkan gambaran kondisi tersebut, maka perlu disusun suatu analisis beban kerja di lingkungan UB agar berbagai permasalahan SDM dapat diselesaikan secara sistematis, komprehensif, dan terukur dalam rangka mewujudkan visi organisasi. Diharapkan dengan adanya analisis beban kerja ini akan diperoleh informasi mengenai tingkat kebutuhan dan pengalokasian sumber daya manusia dalam menyelesaikan beban kerjanya serta tingkat kinerja yang prima dalam berkontribusi terhadap pencapaian sasaran dan tujuan organisasi.

Berdasarkan uraian sebelumnya, maka tujuan penelitian ini adalah: mengetahui jumlah penggunaan waktu kerja yang dibutuhkan tenaga kependidikan, menentukan jumlah kebutuhan tenaga kependidikan yang optimal sesuai dengan standar, dan menjelaskan rekomendasi bagi perguruan tinggi dalam melakukan perencanaan kebutuhan pegawai yang optimal.

\section{Kajian Literatur}

\section{Smart University Governance}

Smart Governance adalah salah suatu konsep yang saat ini sedang mainstream dalam penyelenggaraan perguruan tinggi. Konsep ini adalah turunan dari konsep good governance atau tata kelola pemerintahan yang baik. Tujuan dari konsep ini adalah untuk mewujudkan perguruan tinggi yang akuntabel. Upaya awal pemerintah dalam kerangka implementasi konsep smart university governance adalah dengan membentuk satuan kerja yang menerapkan pola tata kelola kepegawaian dan keuangan badan layanan umum. Satuan Kerja Badan Layanan Umum merupakan satuan kerja yang fokus terhadap pelayanan terbaik kepada publik. 
Sebagai salah satu perwujudan dari konsep smart university governance, perguruan tinggi Badan Layanan Umum (BLU) diwajibkan untuk menerapkan prinsip-prinsip smart governance. Salah satu prinsip smart governance adalah adanya transparansi dan akuntabilitas. Akuntabilitas dan transparansi tersebut dimaksudkan untuk memastikan bahwa pengelolaan keuangan pemerintah yang dilakukan aparatur pemerintah berjalan dengan baik. Di negara demokrasi seperti Indonesia, organisasi publik dituntut untuk akuntabel terhadap seluruh tindakan-tindakan yang telah dilakukannya (Wicaksono, 2015). Smart university governance merupakan konsep pengelolaan yang dapat menunjang keberlangsungan perguruan tinggi (Trakman, 2008; Puspitarini, 2012). Penerapan smart university governance dapat mengurangi kecenderungan fraud. Soleman (2013) menyimpulkan bahwa penerapan smart university governance dapat mencegah terjadinya perilaku fraud di perguruan tinggi.

Implementasi Pola Pengelolaan Kepegawaian Badan Layanan Umum (PPK-BLU) adalah salah satu upaya untuk meningkatkan akuntabilitas publik terutama akuntabilitas pengelolaan sumber daya manusia. Salah satu pendukung implementasi smart university governance yang bisa dilakukan adalah analisis jabatan dan analisis beban kerja. Peraturan Menteri Pemberdayaan Aparatur Negara dan Reformasi Birokrasi (Permenpan-RB) Nomor 33 tahun 2011 menyebutkan bahwa analisis jabatan adalah proses, metode dan teknik untuk memperoleh data jabatan yang diolah menjadi informasi jabatan dan disajikan untuk kepentingan program kepegawaian serta memberikan umpan balik bagi organisasi, tatalaksana, pengawasan dan akuntabilitas (Menpan-RB, 2011).

\section{Perencanaan Sumber Daya Manusia}

Perencanaan tenaga kerja merupakan proses memperkirakan kualitas dan kuantitas sumber daya manusia yang dibutuhkan manusia di masa datang, dan menerapkan usaha-usaha yang harus dilakukan untuk memenuhi kebutuhan tersebut (Pranoto dan Retnowati, 2015). Salah satu kegiatan dalam mendukung hal tersebut yang dimaksud adalah Analisis Beban Kerja (ABK). ABK merupakan salah satu alat yang dapat digunakan untuk memonitor dan mengevaluasi organisasi agar mampu melaksanakan tugas secara akurat, efektif dan efisien serta mewujudkan SDM yang tepat, baik kualitas maupun kuantitas, baik pada setaip lini. Menurut Permen RISTEK-DIKTI Nomor 2 Tahun 2018 ABK adalah metode yang digunakan untuk menentukan jumlah waktu, usaha, dan sumber daya yang diperlukan untuk menjalankan tugas dan fungsi organisasi (Menristek DIKTI, 2018).

Pelaksanaan analisis beban kerja tersebut dilakukan untuk mengetahui secara lebih objektif mengenai kebutuhan tenaga kependidikan, tingkat efektivitas dan efisiensi kerja jabatan/unit, serta prestasi kerja jabatan/unit. Pengukuran beban kerja di FIA UB tersebut dilakukan dengan berpedoman pada Permen RISTEK DIKTI Nomor 2 tahun 2018 tentang Pedoman Analisis Beban Kerjajabatan Pelaksana di Lingkungan Kementerian Riset, Teknologi dan Pendidikan Tinggi (RISTEK DIKTI, 2018) serta Peraturan Rektor Universitas Brawijaya Nomor 44 tahun 2016 tentang Penetapan Jabatan Fungsional Umum Dan Jabatan Fungsional Tertentu (Universitas Brawijaya, 2016).

\section{Analisis Beban Kerja}

Beban kerja merupakan porsi kerja yang diterima seseorang yang disesuaikandengan kemampuan fisik, kognitif maupun keterbatasan seseorang yang menerima beban tersebut. Menurut Jex (1998) Beban kerja adalah jumlah pekerjaan yang harus dilakukan seseorang dengan pengklasifikasian kuantitatif (jumlah pekerjaan yang harus dilakukan) atau kualitatif (kesulitan pekerjaan). Untuk mengetahui jumlah beban kerja yng ditanggung oleh pegawai, dilakukan analisis beban kerja.

Menurut Peraturan Menteri Dalam Negeri Nomor 12 Tahun 2008 (Mendagri, 2008), analisis beban kerja adalah suatu teknik manajemen yang dilakukan secara sistematis untuk memperoleh informasi mengenai tingkat efektivitas dan efisiensi kerja organisasi berdasarkan volume kerja. Analisis beban kerja adalah metode yang bertujuan untuk mengetahui jumlah waktu yang diperlukan tenaga kependidikan untuk menyelesaikan suatu pekerjaan. Dari analisis tersebut diharapkan dapat diketahui jumlah tenaga kerja yang dibutuhkan untuk menyelesaikan suatu pekerjaan, baik dalam unit kerja, departemen, divisi, maupun perusahaan. 


\section{Metode Penelitian}

Jenis penelitian yang digunakan adalah deskriptif, yaitu untuk menggambarkan situasi yang sedang diamati. Sedangkan pendekatan penelitian yang digunakan untuk penelitian ini adalah penelitian kualitatif yang merupakan studi yang mendalam dengan menggunakan teknik pengumpulan data langsung dari subjek dalam lingkungan alamiahnya.

Subyek penelitian ini adalah beban kerja yang dihasilkan oleh 86 (delapan puluh enam) Tenaga Kependidikan dengan Jabatan Fungsional Umum yang tersebar pada 4 (empat) Subbagian di salah satu Fakultas di Universitas Brawijaya yaitu Subbagian Akademik, Subbagian Keuangan dan Kepegawaian, Subbagian Umum dan Barang Milik Negara serta Subbagian Kemahasiswaan dan Alumni.

Pengumpulan data primer terkait deskripsi pekerjaan, rata-rata waktu penyelesaian tugas, dan kuantitas beban tugas diperoleh melalui wawancara, dokumentasi, observasi serta Focus Group Discussion (FGD). Wawancara dan FGD dilakukan pada setiap dan sekumpulan tenaga kependidikan setiap jabatan di setiap Subbagian yang kemudian divalidasi oleh jabatan tertinggi pada setiap Subbagian tersebut. Analisis beban kerja menggunakan dasar waktu kerja, yaitu perbandingan waktu kerja riil dan waktu kerja standar. Beban kerja perhitungan beban kerja riil yang diperoleh dari hasil dokumentasi kinerja, wawancara dan verifikasi dengan tenaga kependidikan dan atasan langsung.

Waktu kerja standar adalah waktu kerja yang ditetapkan oleh pemerintah untuk lingkungan Lembaga pemerintah. Dasar perhitungan waktu kerja adalah sesuai dengan peraturan berikut: (1) Peraturan Meneteri RISTEK DIKTI Nomor 2 tahun 2018 tentang Pedoman Analisis Beban Kerja jabatan Pelaksana Di Lingkungan Kementerian Riset, Teknologi, Dan Pendidikan Tinggi (2) Peraturan Rektor Universitas Brawijaya Nomor 44 tahun 2016 tentang Penetapan Jabatan Fungsional Umum Dan Jabatan Fungsional Tertentu. (3) Keputusan Presiden Nomor 68 tahun 1995 tentang Hari Kerja di Lingkungan Lembaga Pemerintah. berikut:

Perhitungan beban kerja menurut Wignyosubroto (dalam Ihsan et al, 2019) menggunakan rumus sebagai

$$
\begin{aligned}
\mathrm{Wb}=\mathrm{WN} \times \frac{100 \%}{100 \%-\text { Allowance }} \\
\text { dengan }: \mathrm{Wb}=\text { waktu baku, dan } \\
\mathrm{Wn}=\text { waktu normal. } \\
\text { Beban Kerja }=\frac{\text { Waktu Baku }}{\text { Total Waktu Kerja }}
\end{aligned}
$$

Waktu baku dalam penelitian ini menggunakan keputusan Presiden No 68 Tahun 1995 tentang Hari Kerja di Lingkungan Lembaga Pemerintah. Jumlah waktu baku tenaga kependidikan berdasarkan Kepres tersebut adalah 1200 jam per tahun.

Selanjutnya hasil analisis beban kerja akan dianalisis dengan pendekatan model interaktif (interactive model) menurut Miles, Huberman dan Saldana (2014) Aktivitas dalam analisis data kualitatif dilakukan secara interaktif dan berlangsung secara terus-menerus sampai tuntas, sehingga datanya sudah jenuh. Adapun model interaktif yang dimaksud sebagai berikut:

\section{Gambar 1. Model Analisis Data Interaktif}

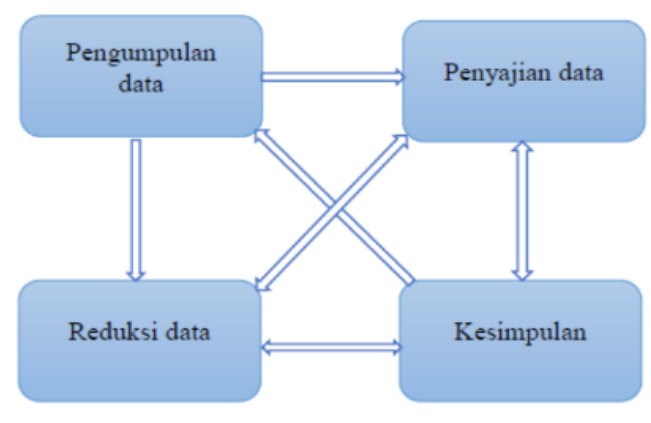

Sumber : Miles, Huberman dan Saldana (2014) 


\section{Hasil Penelitian}

Pada Tahun 2019 tenaga kependidikan yang diverifikasi analisis beban kerja (ABK) total berjumlah $\mathbf{8 6}$ orang, yang menjadi bagian dari empat (4) sub bagian di salah satu Fakultas di Universitas Brawijaya adalah dirinci dalam Tabel berikut:

Tabel 1. Distribusi Jumlah Tenaga Kependidikan

\begin{tabular}{|c|l|c|}
\hline No. & Sub Bagian & Jumlah \\
\hline 1 & Sub Bagian Kemahasiswaan danAlumni & 3 Orang \\
\hline 2 & Sub Bagian Umum dan Barang Milik Negara & 41 Orang \\
\hline 3 & Sub Bagian Keuangan dan Kepegawaian & 11 Orang \\
\hline 4 & Sub Bagian Akademik & 31 Orang \\
\hline \multicolumn{2}{|l}{ Total } & $\mathbf{8 6}$ Orang \\
\hline
\end{tabular}

Sumber: Data diolah (2019)

Berdasarkan Keputusan Presiden Nomor 68 tahun 1995 tentang Hari Kerja di Lingkungan Lembaga Pemerintah. Jam kerja instansi pemerintah adalah 37,5 (tiga puluh tujuh koma lima) jam per minggu dengan rincian:

1. Senin -Kamis $07.30-16.00$ Waktu istirahat $12.00-13.00$

2. Jum'at $07.30-16.30$ Waktu istirahat $12.00-13.30$

Jam kerja efektif adalah jumlah jam kerja formal dikurangi dengan waktu kerja yang hilang karena tidak bekerja (allowance) seperti makan, sholat, dan sebagainya, yaitu 30\% (tiga puluh persen) dari jumlah jam kerja. Berdasarkan Peraturan Kepala Badan Kepegawaian Negara Nomor 19 Tahun 2011 tentang Pedoman Umum Penyusunan Kebutuhan Pegawai Negeri Sipil, jam kerja efektif setelah dikurangi waktu luang adalah sebagai berikut:

1. Jam kerja efektif per hari $=1$ (satu) hari $\times 5$ (lima) jam $=300$ (tiga ratus) menit;

2. Jam kerja efektif per minggu $=5$ (lima) hari $\times 5$ (lima) jam $=25$ (dua puluh lima)jam $=1500$ (seribu lima ratus) menit;

3. Jam kerja efektif per bulan $=20$ (dua puluh) hari $\times 5$ (lima) jam $=100$ (seratus) jam $=6000$ (enam ribu) menit; dan

4. Jam kerja efektif per tahun $=240$ (dua ratus empat puluh) hari $\times 5$ (lima) jam $=1200$ (seribu dua ratus) jam $=72000$ (tujuh puluh dua ribu) menit. Jam kerja efektif akan menjadi alat pengukur dari bobot kerja yang dihasilkan setiap unit kerja.

Berdasarkan hasil wawancara dengan tenaga kependidikan, rata-rata jam kerja efektif per tahun dari 86 tenaga kependidikan yang mengikuti $A B K$ adalah $1.215,77$ jam per tahun, dengan total kebutuhan tenaga kependidikan sebelum dilakukan ABK adalah $89(89,34)$ orang. Namun setelah dilakukan verifikasi dengan atasan langsung dan dilakukan analisis dengan mempertimbangkan jenis pekerjaan, optimalisasi penggunaan teknologi informasi, penyederhanaan prosedur kerja, maka sebenarnya total kebutuhan tenaga kependidikan adalah $85(84,51)$ orang, sehingga terdapat kelebihan jumlah tenaga kependidikan berjumlah 4 (empat) orang, hal tersebut bisa dilihat pada diagram berikut: 
Gambar 2. Total Kebutuhan Tenaga Kependidikan Hasil Verifikasi Analisis Beban Kerja

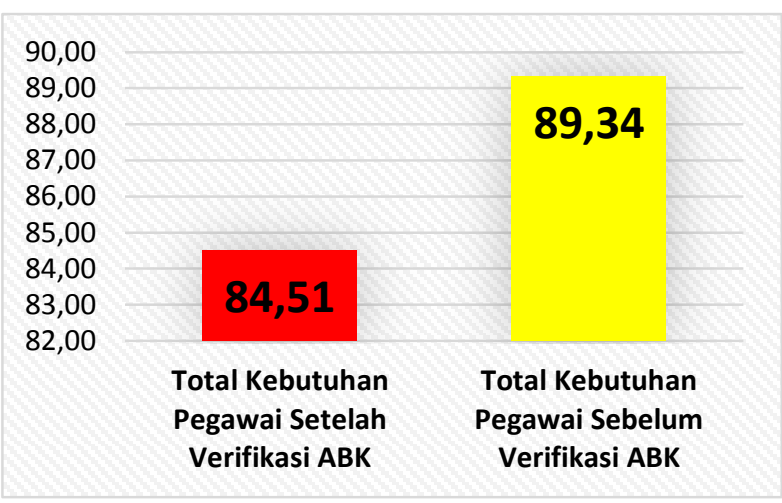

Sumber: Data diolah (2019)

Analisis lebih lanjut, dilakukan untuk mendeteksi tenaga kependidikan yang bekerja melebihi waktu baku, analisis dan verifikasi dengan atasan langsung dan pihak pimpinan Fakultas dan Kepegawaian Universitas. Hasil analisis mengelompokkan beban kerja tenaga kependidikan menjadi empat kriteria yaitu critical underload (sangat kurang), underload (kurang), fit (sesuai), overload (berlebih). Berikut pengelompoka Norma Kerja yang diadaptasi dari hasil penelitian Milyansari (2014).

Tabel 2. Norma Beban Kerja

\begin{tabular}{|l|l|l|}
\hline No & \multicolumn{1}{|c|}{ Perhitungan beban kerja } & Kategori \\
\hline 1 & $<0,7$ & Critical Underload \\
\hline 2 & $0,7 \leq n \leq 0,9$ & Underload \\
\hline 3 & $0,9<n \leq 1$ & Fit \\
\hline 4 & $\geq 1$ & Overload \\
\hline
\end{tabular}

Sumber: Data diolah (2019)

Hasil pengelompokan dapat dilihat pada diagram sebagai berikut:

Gambar 3. Hasil Verifikasi ABK Tenaga Kependidikan

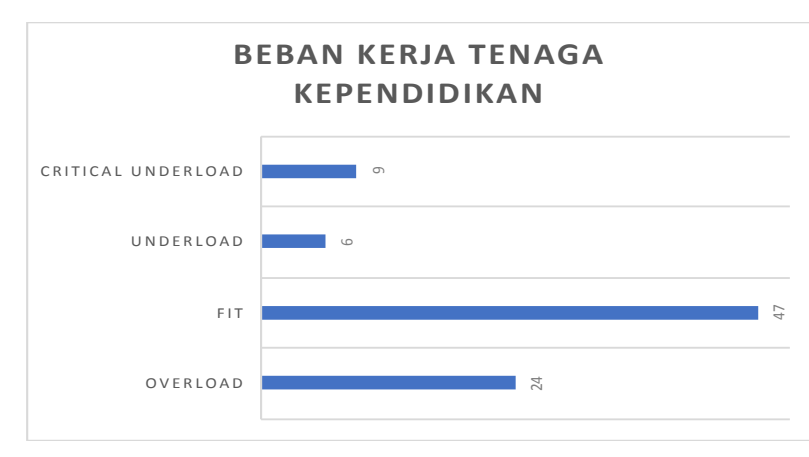

Sumber: Data diolah (2019)

Secara umum, hasil perhitungan ABK tenaga kependidikan per sub bagian menggambarkan bahwa seluruh sub bagian terdapat tenaga kependidikan yang memiliki kesesuaian beban kerja berikut yang mengalami kekurangan beban kerja dan yang mengalami kelebihan beban kerja dengan melihat efektivitas per sub bagian masing-masing. Sub Bagian Kemahasiswaan dan Alumni memiliki 3 (tiga) orang tenaga kependidikan yang mengikuti $A B K$, dengan hasil $A B K$ masing-masing tenaga kependidikan disajikan pada gambar 8 di bawah ini, dapat diketahui masing-masing memiliki beban kerja yang sesuai (fit). 
Gambar 4. Hasil Verifikasi ABK pada Sub Bagian Kemahasiswaan dan Alumni

Sumber: Data diolah (2019)

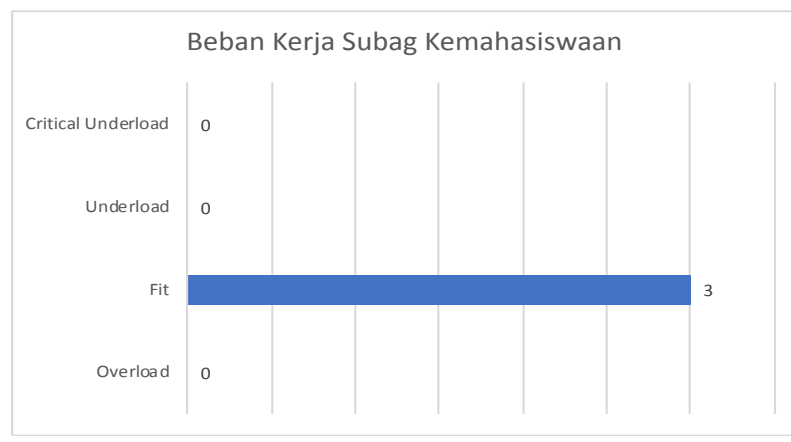

Sub Bagian Umum dan BMN memiliki 31 (tiga puluh satu) orang tenaga kependidikan yang mengikuti ABK, dengan hasil $\mathrm{ABK}$ masing-masing tenaga kependidikan disajikan pada gambar 10 di bawah ini, dapat diketahui terdapat 16 (enam belas) tenaga kependidikan memiliki beban kerja yang sesuai (fit), kemudian 14 (empat belas) tenaga kependidikan memiliki beban kerja berlebih (overload) dan terdapat 1 (satu) tenaga kependidikan yang memiliki beban kerja sangat kurang (critical underload).

Gambar 5. Hasil Verifikasi ABK pada Sub Bagian Umum dan Barang Milik Negara (BMN)

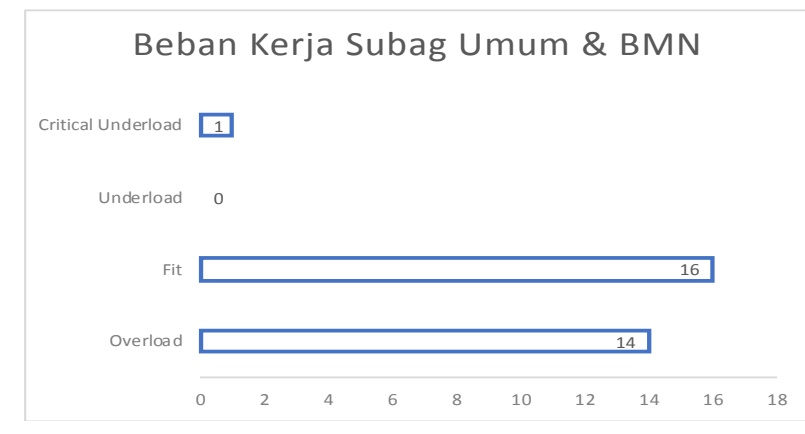

Sumber: Data diolah(2019)

Sub Bagian Keuangan dan Kepegawaian memiliki 11 (sebelas) orang tenaga kependidikan yang mengikuti $A B K$, dengan hasil $A B K$ masing-masing tenaga kependidikan disajikan pada diagram di atas, dapat diketahui terdapat 8 (delapan) tenaga kependidikan memiliki beban kerja yang sesuai (fit), kemudian $\mathbf{3}$ (tiga) tenaga kependidikan memiliki beban kerja berlebih (overload).

Gambar 6. Hasil Verifikasi ABK pada Sub Bagian Keuangan dan Kepegawaian

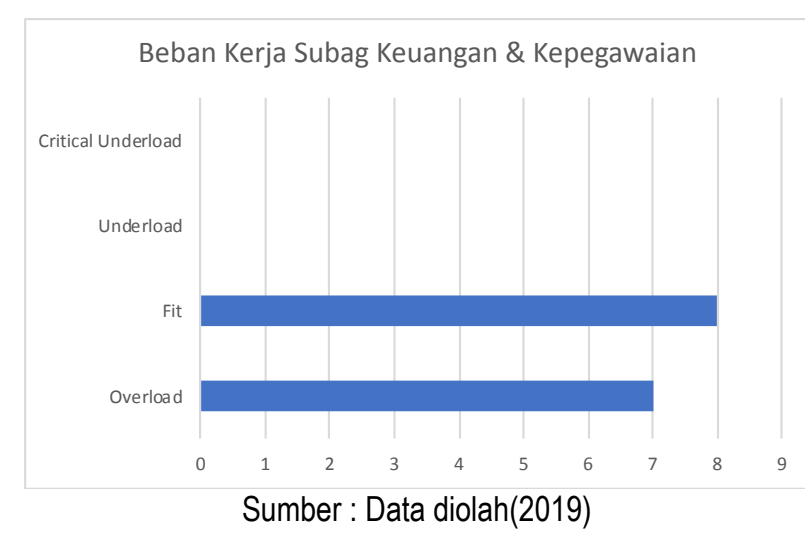


Sub Bagian Akademik memiliki 41 (empat puluh satu) orang tenaga kependidikan yang mengikuti ABK, dengan hasil ABK masing-masing tenaga kependidikan disajikan pada diagram di atas, dapat diketahui terdapat 20 (dua puluh) tenaga kependidikan memiliki beban kerja yang sesuai (fit), kemudian 7 (tujuh) tenaga kependidikan memiliki beban kerja berlebih (overload), terdapat 6 (enam) tenaga kependidikan yang memiliki beban kerja kurang (underload) dan terdapat 8 (delapan) tenaga kependidikan yang memiliki beban kerja sangat kurang (critical underload).

\section{Gambar 7 Hasil Verifikasi ABK pada Sub Bagian Akademik}

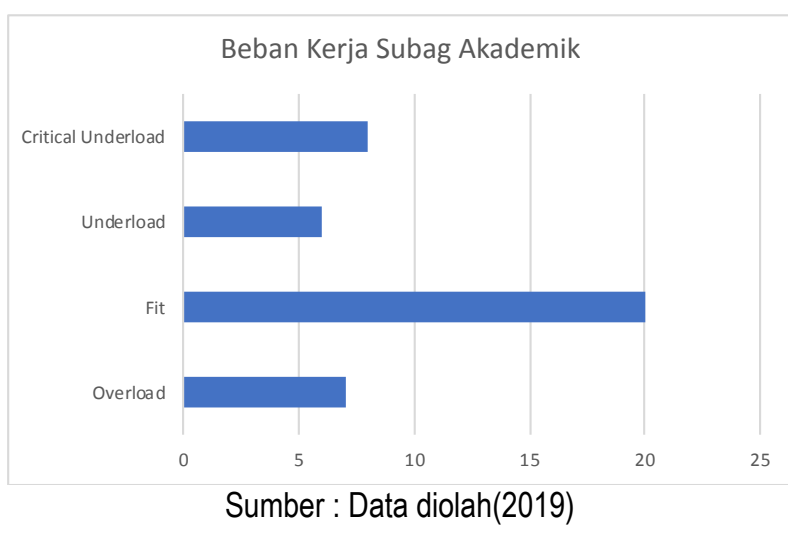

\section{Pembahasan}

Berdasarkan hasil verifikasi beban kerja, mayoritas tenaga kependidikan sudah sesuai dengan standar baku beban kerja, namun masih ada yang overload. Beban kerja tidak hanya menghitung waktu yang dihabiskan untuk pekerjaan produktif tetapi juga termasuk menghitung aspek manusia, seperti kelelahan, kebutuhan pribadi, dan faktor kelonggaran (Barnes dalam Hutagalung dan Gustomo, 2013). Pegawai yang kelebihan beban kerja perlu mendapat perhatian. Karena sebagai manusia akan mengalami kelelahan, jika terus menerus bekerja yang melebihi kapasitas fisiknya. Selain itu pegawai juga sebagai makhluk sosial yang membutuhkan kelonggaran dalam bekerja sehingga bisa memenuhi kebutuhan social baik di lingkungan kerja atau keluarga. Hasil penelitian Utami et al (2020) menyarankan perlu tindakan lebih lanjut yang dilakukan baik perusahaan maupun pihak diluar perusahaan untuk membantu meringankan beban kerja yang terlalu tinggi atau over load agar terhindar dari stres kerja.

Bagi pegawai yang beban kerjanya masih dibawah standar baku, baik critical underload atau underload perlu dilakukan perubahan dalam tugas-tugasnya, atau dilakukan analisis pada jabatan atau tugas pokok dan tambahannya. Karyawan yangbeban kerjanya rendah akan menimbulkan in effisiensi dalam organisasi karena banyaknya waktu menganggur pada karyawan. Selain juga dapat menimbulkan ketidakadilan dalam pembayaran. Hasil penelitian Arifin et al (2016) menyebutkan bahwa evaluasi dan analisa beban kerja secara menyeluruh perlu dilakukan agar tercipta beban kerja yang optimal, beban kerja yang kurang (under load) dan kelebihan beban kerja (over load) masing-masing akan mempunyai dampak seperti kebosanan dan stress yang dapat menyebabkan menurunya komitmen organisasional. Oleh karena itu langkah yang dapat dilakukan adalah melakukan pengurangan dan penambahan jumlah waktu kerja tenaga kependidikan dengan jalan mengalihtugaskan sebagian tenaga kependidikan yang memiliki beban kerja kurang dan sangat kurang, dengan menugaskannya pada sub bagian lainnya yang memiliki beban kerja terlalu tinggi (overload) atau kekurangan tenaga kependidikan, sehingga seluruh tugas dan fungsi dapat dijalankan secara lebih efektif dan efisien. Informasi beban kerja akan digunakan untuk menghitung jumlah kebutuhan karyawan.

Informasi beban kerja juga dapat digunakan untuk memprediksi kebutuhan karyawan di masa depan. Hasil penelitian Purnomo (2015) menunjukkan bahwa analisis beban kerja digunakan untuk menentukan jumla karyawan dengan metode penghitungan waktu menggunakan stopwatch untuk menentukan jumlah waktu yang diperlukan dalam menyelesaikan pekerjaan karyawan bank. Terdapat sejumlah karyawan yang over load dengan nilai kalkulasi 1,04. Penelitian pada perawat rumah sakit yang dilakukan oleh Swiger et al., (2016) menemukan bahwa analisis beban kerja dapat membantu para pemimpin mempertimbangkan dan mengidentifikasi beban kerja yang tidak perlu, berlebihan, atau lebih tepat untuk penugasan kepada anggota tim perawatan kesehatan lainnya. Hasil kedua penelitian tersebut menunjukkan bahwa hasil analisis beban kerja dapat dijadikan dasar oleh perusahaan untuk menambah karyawan. Jumlah karyawan sesuai dengan beban kerja akan mendukung 
kebutuhan karyawan dalam perencanaan strategis. (Hutagalung dan Gustomo, 2013). Dengan melihat hasil dari analisis beban kerja di atas, perencanaan strategis yang perlu dilakukan adalah menyempurnakan tatakelola sekaligus melakukan peninjauan kembali alokasi tugas, wewenang dan tanggungjawab tiap jabatan. Mendukung pendapat di atas, hasil analisis beban kerja dapat juga digunakan untuk mengenali tren perubahan permintaan pelanggan sekaligus perubahan pekerjaan di masa depan. (Gmach et al 2007). Selain itu, Sunday dan Rosemary (2017) yang melakukan penelitian pada staf akademik dan administrasi di perguruan tinggi di Nigeria menyampaikan bahwa strategi untuk mengelola beban kerja diantaranya adalah; mengatur waktu dengan tepat, memprioritaskan berbagai pekerjaan, selalu beristirahat sejenak atau liburan. Jika strategi ini ditaati oleh dosen dan administrasi, beban kerja akan dikelola sebagian besar dan dosen Nigeria akan bekerja dan semangat kembali bekerja.

Perguruan Tinggi memiliki visi, misi dan tujuan yang disesuaikan dengan kondisi perubahan lingkungan. Visi, misi dan tujuan tersebut harus dapat dijabarkan dengan baik agar tercapai efektivitas dan efisiensi organisasi. Penjabaran tujuan tersebut berasal dari tujuan organisasi yang selanjutnya akan dijabarkan pada tingkat unit kerja. Penjabaran visi, misi dan tujuan perusahaan secara keseluruhan dapat dilakukan dengan perencanaan SDM dari awal secara baik. Perencanaan SDM merupakan salah satu faktor yang menentukan kesuksesan suatu organisasi. Ketika organisasi berhasil merencanakan SDMnya dengan baik maka akan diperoleh tenaga kependidikan yang dapat bekerja dengan aktif pada posisi yang tepat. Perencanaan SDM dalam dilakukan dengan analisis pekerjaan yang dilakukan dengan menjabarkan deskripsi pekerjaan dan spesifikasi pekerjaan. Untuk mendukung analisis pekerjaan digunakan analisis beban kerja yang dilakukan dengan menganalisis jumlah beban kerja dan kebutuhan tenaga kerja. Oleh karena itu, adanya gambaran kesesuaian atau ketidaksesuaian antara analisis pekerjaan dan analisis beban kerja dapat menghasilkan pelaksanaan pekerjaan secara efektif dan efisien serta tercapainya kinerja tenaga kependidikan, Fakultas dan Universitas. Tujuan Fakultas melaksanakan perencanaan SDM adalah agar dapat mengidentifikasi tugas-tugas yang akan dilaksanakan oleh setiap tenaga kerja sehingga tugas yang diberikan dapat diselesaikan dengan baik dan sesuai dengan target kinerja. Beban kerja yang ditetapkan harus cukup karena beban kerja dapat memberikan dampak pada hasil pekerjaan. Di dalam setiap unit memiliki beban kerja yang berbeda sehingga kesesuaian antara beban kerja dan jumlah tenaga kerja dalam unit tersebut dapat dianalisis. Jika terdapat ketidaksesuaian antara beban kerja dan jumlah tenaga kerja yang ada, maka dapat dilakukan penambahan atau pengurangan tenaga kerja dalam unit tersebut.

\section{Kesimpulan}

Penggunaan waktu kerja oleh tenaga kependidikan dibagi menjadi 4 kategori yaitu overload, fit, underload, dan critical underload. Hal tersebut merupakan hasil verifikasi waktu riil yang digunakan untuk menyelesaikan pekerjaan pokok dan tambahan dibandingkan dengan standar Keputusan Presiden Nomor 68 tahun 1995 tentang Hari Kerja di Lingkungan Lembaga Pemerintah.

Total kebutuhan tenaga kependidikan setelah verifikasi adalah 84 orang. Hasil analisis beban kerja dapat digunakan sebagai salah satu alat diagnostik oleh Pimpinan untuk melakukan penataan organisasi, penajaman dan optimalisasi tugas dan fungsi. Penyeimbangan beban kerja antara sub bagian dilakukan dengan meninjau kembali pembagian tugas/beban kerja per sub bagian, serta meningkatkan pelaksanaan monitoring dan evaluasi sesuai tugas serta fungsi masing-masing sub bagian, berikut disertai usaha peningkatan jaminan mutu pelayanan dan pembinaan terhadap pelaksanaan tugas masing-masing sub bagian.

\section{Saran}

Fakultas dapat membuat perencanaan untuk kemudaian mengusulkan ke Universitas dalam hal melakukan penambahan dan pengurangan jumlah tenaga kependidikan. Salah satu cara yang dapat dilakukan untuk menyesuaiakan beban kerja adalah dengan jalan mengalihtugaskan sebagian tenaga kependidikan yang memiliki beban kerja kurang dan sangat kurang, dengan menugaskannya pada sub bagian lainnya yang memiliki beban kerja terlalu tinggi (overload) atau kekurangan tenaga kependidikan, sehingga seluruh tugas dan fungsi dapat dijalankan secara lebih efektif dan efisien

Perguruan Tinggi perlu semakin memperkuat tata kelola kelembagaan dan sistem dokumentasi kepegawaian untuk memudahkan penghitungan analisis beban kerja, menyesuaikan SOP sesuai dengan 
perkembangan yang terjadi dan/atau menyusun SOP baru, melakukan pemetaan kompetensi dan penataan SDM sehingga diketahui kebutuhan riil SDM termasuk kebutuhan jabatan fungsional tertentu (JFT), melakukan analisis kebutuhan SDM berdasarkan tugas-tugas yang belum tertangani, tambahan fungsi, tambahan beban tugas dan penyesuaian struktur organisasi.

Oleh karena itu, dengan disarankan agar perguruan tinggi melakukan analisis beban kerja ketika ada perubahan pelayanan misalnya bertambahnya atau berkurangnya program studi, perubahan jumlah mahasiswa, atau perubahan dalam pelayanan tridharmanya. Untukk selanjutnya perguruan tinggi melakukan penataan tenaga kependidikan sesuai dengan jumlah yang dibutuhkan pada masing-masing sub bagian, membuat penyederhanaan tugas yang memungkinkan pengurangan waktu yang dibutuhkan, mengoptimalisasikan penggunaan teknologi sebagai alat bantu untuk memangkas waktu kerja, menempatkan pegawai sesuai dengan kualifikasi yang dibutuhkan pada masing-masing tugas.

\section{Daftar Pustaka}

Arifin. Z., Alhabsji, T., dan Utami, HN., 2016. Pengaruh Beban Kerja dan Kompensasi terhadap Komitmen Organisasional dalam Upaya Meningkatkan Kinerja Karyawan. Jurnal Bisnis dan Manajemen. Vol. 3 (2) 64-75

Creswell, JW., (2016). Research Design: Pendekatan Metode Kualitatif, Kuantitatif, dan Campuran. Yogyakarta: Pustaka Pelajar.

Gmach, D., Rolia, J., Cherkasova, L., and Kemper, A., (2007). "Workload analysis and demand prediction of enterprise data center applications," IEEE 10th International Symposium On Workload Characterization, Boston, Ma, 2007, Pp. 171-180, Doi: 10.1109/liswc.2007.4362193.

Houston, D., Meyer, LH., Paewai, S., (2006), Academic Staff Workloads and Job Satisfaction: Expectations and values in academe, Journal of Higher Education Policy and Management Vol. 28, No. 1, March 2006, pp. 17-30.

Hutagalung, R, Gustomo, A, (2013), Workload Analysis For Planning Needs Of Employees In The Corporate Administration Unit Pt Timah (Persero) Tbk, The Indonesian Journal Of Business Administration Vol. 2, No. 19, 2013:2290-2297

Ihsan, M, Fathimahhayati, L.D, dan Parwita, T.A. (2019), Analisis Beban Kerja dan Penentuan Tenaga Kerja Optimal Dengan Metode Workload Analysis Dan ECRS, JIME (Journal of Industrial and Manufacture Engineering), 3(2): 72-78.

Kementerian Dalam Negeri RI. (2008). Peraturan Menteri Dalam Negeri Nomor 12 Tahun 2008 tentang Pedoman Analisis Beban Kerja Di Lingkungan Depdagri dan Pemerintah Daerah. Jakarta: Kementerian Dalam Negeri RI.

Kementerian RISTEK-DIKTI RI. (2018.). Permen RISTEK-DIKTI Nomor 2 Tahun 2018 tentang Pedoman Analisis Beban Kerja Jabatan Pelaksana di Lingkungan Kementerian RISTEK-DIKTI. Jakarta: Kementerian RISTEK-DIKTI RI.

Miles, M.B, Huberman, A.M, dan Saldana, J. (2014).Qualitative Data Analysis: A Methods Sourcebook, Edition 3. USA: Sage Publications.

Milyansari, W, (2014). Analisis Beban Kerja Pada PT PLN (Persero) Rayon Ngagel Surabaya Calyptra: Jurnal IImiah Mahasiswa Universitas Surabaya Vol.3 No.1

Pranoto L.H, Retnowati, (2015). Analisis Beban Kerja Sumber Daya Manusia Perusahaan. Jakarta : PPM.

Purnomo, H., (2015), Workload analysis for determining the number of employees at banking companies, Gema, Vol 27, No 50. 2068-2076

Puspitarini, N.D. (2012). Peranan Satuan Pengawas Internal dalam pencapaian Good University Governance pada perguruan tinggi berstatus Pola Pengelolaan Keuangan Badan Layanan Umum (PK-BLU). AAJ. Vol:1, No.2.ISSN 2252-6765.

Sunday, O.,D., and Rosemary, E., (2017), Managing Workload of Academic Staff for Job Effectiveness in Nigerian Universities: A Study of University of Port Harcourt in South-South Geopolitical Zone of Nigeria, Journal of Humanities Social Sciences and Education (IJHSSE) Volume 4, Issue 12, December 2017, PP 102-108, http://dx.doi.org/10.20431/2349-0381.0412013.

Jex, S.M., (198) Stress and job performance: theory, research, and implications for managerial practice, Thousan Oaks, CA, Sage. 
Swiger, P.A., Vance, D.E., Patrician, P.A., (2016) Nursing workload in the acute-care setting: A concept analysis of nursing workload, Nursing Outlook, Vol 64, Issue 3, 244-254

Trakman, L., (2008). Modelling University Governance. Higher Education Quarterly, Volume 62, No. 1/2, January-April.

Universitas Brawijaya. (2016). Peraturan rektor Universitas Brawijaya nomor 44 tahun 2016 tentang penetapan jabatan fungsional umum dan jabatan fungsional tertentu. Malang: Universitas Brawijaya.

Utami, HN, Afrianty, TW, Sari, RW, (2019) Beban kerja dan pengaruhnya terhadap komitmen organisasional dengan stres kerja sebagai variabel intervening, Jurnal Bisnis Terapan Vol 3 No 2, es 2019, Politeknik Ubaya, Surabaya.

Wicaksono, K.W. (2015). Akuntabilitas organisasi sektor publik. JKAP, Vol:19, No.1. 